\title{
Properties of the $\beta$-Glucosidases of Talaromyces emersonii
}

\author{
By ANTHONY MCHALE ANd MICHAEL P. COUGHLAN* \\ Department of Biochemistry, University College, Galway, Ireland
}

(Received 10 December 1981; revised 5 February 1982)

\begin{abstract}
The thermophilic fungus Talaromyces emersonii when grown on cellulose-containing medium produces three extracellular forms of $\beta$-glucosidase, I $\left(M_{\mathrm{r}}, 135000\right)$, II $\left(M_{\mathrm{r}}, 100000\right)$, III $\left(M_{\mathrm{r}}\right.$, $45700)$, and one intracellular form, $\beta$-glucosidase IV $\left(M_{\mathrm{r}}, 57600\right)$. With the exception of $\beta$ glucosidase II which has yet to be isolated in quantities sufficient for characterization each has been shown to be a glycoprotein and to exist as a single polypeptide. Each of the purified enzyme preparations catalysed cellobiose hydrolysis but only $\beta$-glucosidase IV, at the concentrations of substrates used, also catalysed glucosyl transfer to cellobiose.
\end{abstract}

\section{INTRODUCTION}

The extracellular cellulase system of the thermophilic fungus, Talaromyces emersonii, is comprised of a number of endocellulases (EC 3.2.1.4), exocellulases (EC 3.2.1.91) and three forms of $\beta$-glucosidase (EC 3.2.1.21) (McHale \& Coughlan, 1980, 1981 $a$ ). The latter enzymes can be separated from one another by polyacrylamide gradient gel electrophoresis and on the basis of their relative mobilities have been termed $\beta$-glucosidases I, II and III (McHale $\&$ Coughlan, $1981 a$ ). Two of these, viz. $\beta$-glucosidases I and III, and an intracellular form, $\beta$-glucosidase IV, were isolated in sufficient quantity to permit their characterization (McHale \& Coughlan, $1981 b$ ). In this paper we present the results of further investigations on the properties of these enzymes.

\section{METHODS}

Chemicals. Chemicals were obtained from the following suppliers: purified ball-milled spruce cellulose (BW.40) was from Brown \& Co., Berlin, N.H., U.S.A.; corn steep liquor from Biocon Ltd, Cork, Republic of Ireland; nonionic detergent (NP-40) from Shell Chemicals (Ireland), Dublin; SDS, Blue dextran, $p$-nitro-phenyl- $\beta$-D-glucoside, acrylamide and $N, N^{\prime}$-methylene-bis-acrylamide from Sigma; dinitrosalicylate, sulphosalicylic acid, PAGE blue 83 and $N, N, N^{\prime}, N^{\prime}$-tetramethylethylene diamine (TEMED) from BDH; Pharmalytes, high and low molecular weight protein calibration kits, isoelectric focusing apparatus (FEB 3000) and the electrophoresis constant power supply (ECPS 3000/150) from Pharmacia.

Organism. Talaromyces emersonii CBS 814.70 obtained from Centraal Bureau voor Schimmelcultures, Baarn, The Netherlands was grown at $45^{\circ} \mathrm{C}$ as described earlier (Folan \& Coughlan, 1978, 1981) on medium containing $2 \%(\mathrm{w} / \mathrm{v})$ cellulose $0.5 \%(\mathrm{w} / \mathrm{v})$ corn steep liquor and $1 \%(\mathrm{w} / \mathrm{v}) \mathrm{NH}_{4} \mathrm{NO}_{3}$.

Enzyme purification and assay. The various enzymes displaying $\beta$-glucosidase (cellobiase) activity were assayed and purified to homogeneity (as judged by polyacrylamide gradient gel electrophoresis by the procedures reported earlier (Folan \& Coughlan, 1978; McHale \& Coughlan, 1980, 1981 b).

Protein and carbohydrate determination. Protein concentration was measured by the method of Hartree (1972). The carbohydrate content of purified enzyme samples was determined using a scaled-down version of the method of Dubois et al. (1965). Samples $(0.2 \mathrm{ml})$ of each enzyme solution were incubated at $28^{\circ} \mathrm{C}$ for $15 \mathrm{~min}$ with $10 \mu \mathrm{l}$ phenol/water $\left(80 \%\right.$, w/v) and $1 \mathrm{ml} \mathrm{H}_{2} \mathrm{SO}_{4}$ (sp. gr. 1.84). Absorbance of the mixture at $490 \mathrm{~nm}$ was measured and the carbohydrate content as mannose equivalents calculated by reference to a mannose standard curve. Under the conditions used $10 \mu \mathrm{g}$ of mannose gave an $A_{490}$ of 0.56 .

Electrophoresis and gel filtration. Subunit molecular weights of the various enzymes exhibiting $\beta$-glucosidase activity were estimated by subjecting samples of the purified preparations to SDS-polyacrylamide gradient gel electrophoresis (Margolis \& Kenrick, 1968) following pretreatment of unknowns and of calibration standards as recommended by Pharmacia (publication no. 11-B-037-01, August 1978). Thus, unknowns and standards were 
dissolved in $88.7 \mathrm{~mm}$-Tris $/ 2.5 \mathrm{~mm}$-disodium EDTA $/ 81.5 \mathrm{~mm}$-boric acid, $\mathrm{pH} 8.3$, containing $0.6 \%$ (w $/ \mathrm{v}$ ) SDS and $5 \%(\mathrm{v} / \mathrm{v}) 2$-mercaptoethanol and heated at $100{ }^{\circ} \mathrm{C}$ for $5 \mathrm{~min}$. The running buffer was Tris/disodium EDTA/boric acid, $\mathrm{pH} 8 \cdot 3$, as above but containing $0 \cdot 1 \%(\mathrm{w} / \mathrm{v})$ SDS. Gels were fixed in water $/$ methanol $(7: 3, \mathrm{v} / \mathrm{v})$ containing trichloroacetic acid $\left(114 \mathrm{~g} \mathrm{l}^{-1}\right)$ and sulphosalicylic acid $\left(34 \mathrm{~g} \mathrm{l}^{-1}\right)$ followed by staining for protein in $0.2 \%(\mathrm{w} / \mathrm{v})$ PAGE blue 83 in water/methanol/acetic acid $(6: 6: 1$, by vol.). Gels were destained in water $/ \mathrm{methanol} /$ acetic acid ( $6: 6: 1$, by vol.) until the background was clear. Molecular weights were estimated by gel filtration on a column of Sephadex G-200 $(1.2 \times 25.5 \mathrm{~cm})$ equilibrated with $20 \mathrm{mM}$-Tris $/ \mathrm{HCl}$ buffer, $\mathrm{pH} 7 \cdot 5$. Standards and unknowns eluted with the same buffer were detected by their absorbance at $280 \mathrm{~nm}$. The void volume was determined using Blue dextran.

Isoelectric focusing. This technique was carried out using Pharmalytes covering the $\mathrm{pH}$ range 2.5 to $5 \cdot 0$ and the procedure recommended by Pharmacia (publication no. 01-900-2-1464-02). $\beta$-Glucosidase I was also subjected to isofocusing in the presence of urea $(9 \mathrm{M})$ and the non-ionic detergent NP-40 $(3 \%, \mathrm{v} / \mathrm{v})$ as recommended by M. L. O'Connor \& D. R. Headon (personal communication). Gels were stained for $\beta$-glucosidase activity as described previously (McHale \& Coughlan, 1981a). After each run the $\mathrm{pH}$ gradient was determined by measurement of $\mathrm{pH}$ in samples of gel scraped from various points between the electrode strips from which the Pharmalytes were eluted into $1 \mathrm{ml}$ of degassed distilled water.

\section{RESULTS AND DISCUSSION}

\section{Molecular weights, isoelectric points and carbohydrate contents}

The native molecular weights of the $\beta$-glucosidases were estimated by gel filtration (Fig. 1). The values obtained are in close agreement with the corresponding subunit molecular weight values determined by SDS-polyacrylamide gradient gel electrophoresis of proteins that had been fully reduced with mercaptoethanol (Fig. 1 and Table 1). As these $\beta$-glucosidases are glycoproteins (see below), we must treat with caution the molecular weight values obtained by using the above techniques (see e.g. Andrews, 1965). Nevertheless, since all three enzymes migrated as a single component in both analyses it is clear that each is a single polypeptide.

$\beta$-Glucosidase III also migrated as a single band, pI $3 \cdot 6$, on isoelectric focusing. In contrast, isofocusing of purified preparations of $\beta$-glucosidase I and $\beta$-glucosidase IV showed evidence of heterogeneity. With the former staining for activity gave a more or less continuous smear between points corresponding to $\mathrm{pH}$ values 3.40 and $4 \cdot 17$. A similar smear was obtained after staining for glycoprotein by the method of Zacharius et al. (1969). The formation of different size aggregates of enzyme as a cause of such smearing was ruled out, since the inclusion of urea and the non-ionic detergent NP-40 in the isofocusing process did not lessen the smearing. In the case of $\beta$-glucosidase IV three distinct bands, with pI values $4.41,4.47$ and 4.50 were obtained. All three bands stained for glycoprotein.

We expect that this 'microheterogeneity' of $\beta$-glucosidase I reflects variation in the content or composition of its carbohydrate rather than differences in primary structure and that the same could well be true for $\beta$-glucosidase IV. If this is so, then the carbohydrate contents listed for $\beta$ glucosidases I and IV (Table I) must be considered as average values. Differences between the carbohydrate contents of the three enzymes are highlighted when expressed as mannose equivalents per mol enzyme. These are as follows (depending on whether the calculation was based upon the molecular weight values obtained by gel filtration or by electrophoresis, Table 1): $\beta$ glucosidase I, 382-391; $\beta$-glucosidase III, 59-66; $\beta$-glucosidase IV, 35-38. The extracellular enzymes, viz. I and III have greater carbohydrate contents than has $\beta$-glucosidase IV, the intracellular form. Hayashida \& Yoshioka (1980) have shown that the carbohydrate moieties of the cellulases from Humicola insolens contribute significantly to the thermal stability of these enzymes. This situation may also obtain for $\beta$-glucosidases I, III and IV which have half lives $\left(70^{\circ} \mathrm{C}, \mathrm{pH}\right.$ ) of $410 \mathrm{~min}, 175 \mathrm{~min}$ and $2 \mathrm{~min}$, respectively (McHale \& Coughlan, $1981 \mathrm{~b}$ ), although $\beta$-glucosidases III and IV have a small difference in carbohydrate content for such a large difference in thermal stability.

\section{Transferase activity}

Synthesis of the cellulase system of $T$. emersonii is induced by the presence of cellulosic materials in the growth medium (Folan \& Coughlan, 1978). However, the identity of the actual 

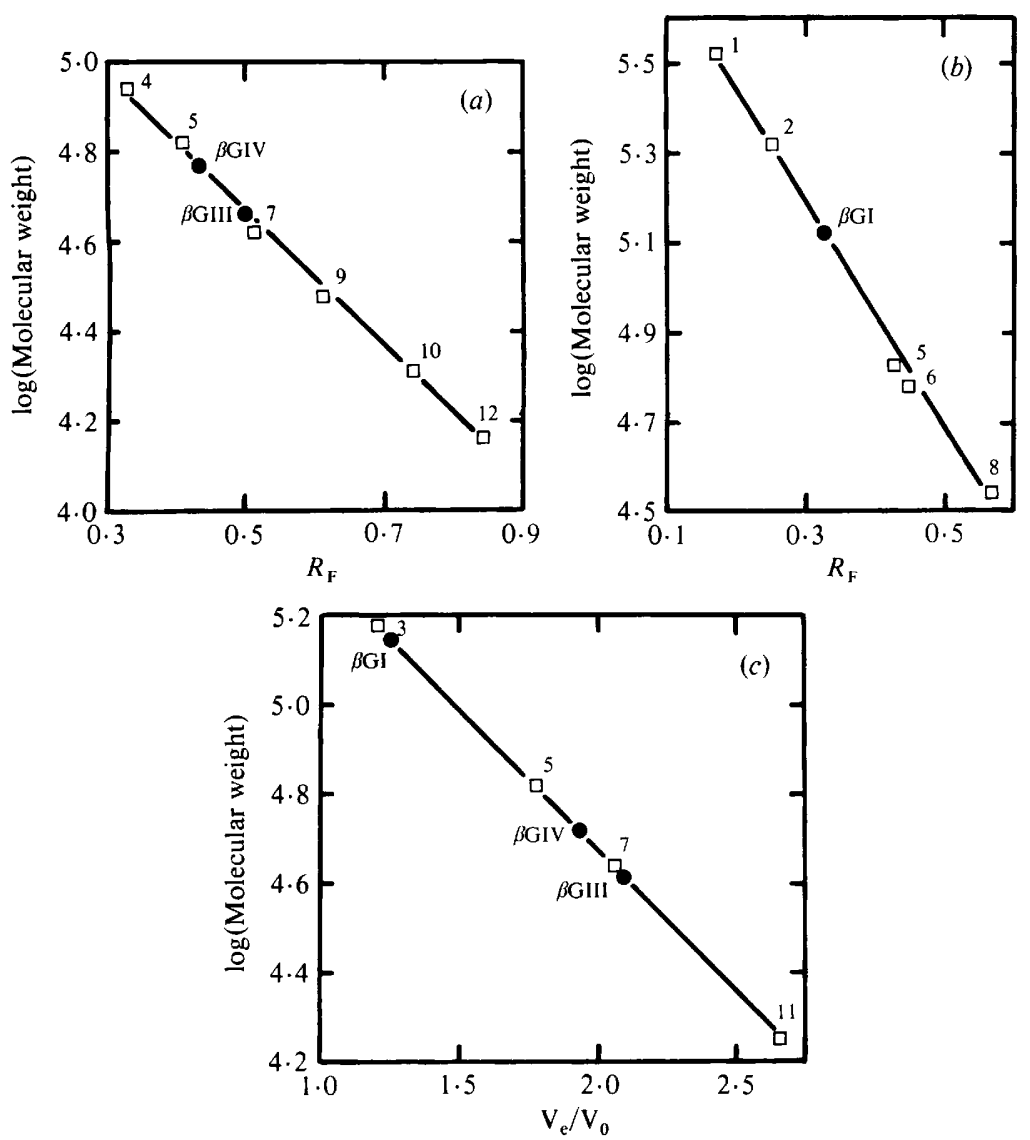

Fig. 1. Molecular weights of the $\beta$-glucosidases of $T$. emersonii. Subunit molecular weights were estimated by polyacrylamide gradient gel electrophoresis in the presence of $\operatorname{SDS}(a, b)$. Molecular weights were estimated by gel filtration on Sephadex G-200 $(1.2 \times 25.5 \mathrm{~cm})$ equilibrated with $20 \mathrm{mM}$ Tris/ $\mathrm{HCl}, \mathrm{pH} 7 \cdot 5(c)$. Standards and their molecular weights $\left(M_{\mathrm{t}} \times 10^{-3}\right)$, were as follows: 1 , thyroglobulin $(330) ; 2$, ferritin (half unit, 220);3, uricase $(150) ; 4$, phosphorylase b (94); 5 , bovine serum albumin $(67) ; 6$, catalase $(60) ; 7$, ovalbumin $(43) ; 8$, lactate dehydrogenase $(36) ; 9$, carbonic anhydrase (30); 10 , trypsin inhibitor $(20 \cdot 1) ; 11$, myoglobin $(17 \cdot 2) ; 12, \alpha$-lactalbumin (14.4). $\beta$ GI, $\beta$ GIII and $\beta$ GIV are defined in the Introduction and in the legend to Table $I$.

Table 1. Properties of the $\beta$-glucosidases of Talaromyces emersonii

Three extracellular forms of $\beta$-glucosidase, $\beta \mathrm{GI}, \beta \mathrm{GII}$ and $\beta \mathrm{GIII}$ and an intracellular form, $\beta \mathrm{GIV}$, are produced by $T$. emersonii. Molecular weight was determined by gel filtration of purified preparations on Sephadex G-200. Subunit molecular weight was determined by electrophoresis under denaturing conditions in polyacrylamide gradient gels.

\section{Property $\quad \beta$ GI $\quad \beta$ GII $\quad \beta$ GIII $\quad \beta$ GIV}

Molecular weight

$\left(\times 10^{-3}\right)$
Subunit molecular
weight $\left(\times 10^{-3}\right)$

pI

Carbohydrate content

$(\%)$

$\begin{array}{cccc}138 & - & 40 \cdot 7 & 52 \cdot 5 \\ 135 & 100^{*} & 45 \cdot 7 & 57 \cdot 6 \\ 3 \cdot 40-4 \cdot 17 & - & 3 \cdot 60 & 4 \cdot 41 \\ & & & 4 \cdot 50 \\ 51 & - & 26 & 12\end{array}$

* The value for (subunit) molecular weight of $\beta$ GIII is a tentative one from electrophoretic analysis as this enzyme has not been purified. 


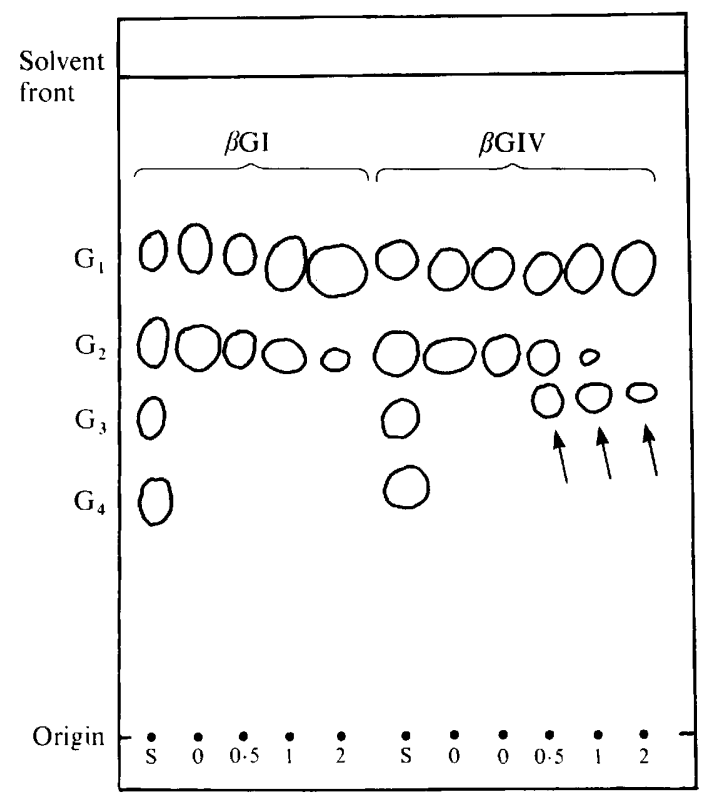

Fig. 2. TLC analysis of the products of action of $\beta$-glucosidase on a mixture of cellobiose and glucose. $\beta$ glucosidases I $(3 \mu \mathrm{g})$ or IV $(30 \mu \mathrm{g})$ were incubated at $37^{\circ} \mathrm{C}$ with $4 \mathrm{~mm}$-cellobiose plus $4 \mathrm{~mm}$-glucose in 50 mM-sodium acetate buffer, $\mathrm{pH} 5$. Samples of reaction mixture were obtained at $0 \cdot 5,1$ and $2 \mathrm{~h}$ after the start of the incubation, boiled for 2 min and subjected to TLC as described by Wood \& McCrae (1978) except that chromatograms were stained with iodine vapour (Dawson et al., 1969). $G_{1}, G_{2}, G_{3}$ and $G_{4}$ refer to the glucose, cellobiose, cellotriose and cellotetraose standards. $G_{3}$ and $G_{4}$ were prepared as described before (McHale \& Coughlan, 1981 b). S indicates standard mixtures of sugars.

inducer(s) of this or any other cellulase system is not yet known. It is generally believed that low constitutive levels of cellulases cleave cellulose and provide a small molecule which on being transported into the cell brings about an increase in the rate of synthesis of the enzymes in question. Mandels \& Reese (1960) reported that during growth of Trichoderma reesei on cellobiose, products of glucosyl transfer were found in the growth medium and that these were better than cellobiose as inducers of cellulase synthesis. Sophorose, a $\beta$-1,2-linked dimer of glucose, is said to be the most potent inducer of cellulase synthesis by Trichoderma reesei (Mandels et al., 1962) although it may not induce all of the components obtained in the presence of cellulose (Sternberg \& Mandels, 1979). While sophorose and other $\beta$-linked di- and trisaccharides have yet to be tested as possible inducers of cellulase synthesis by $T$. emersonii, it was of interest to determine whether any of the $\beta$-glucosidases produced by this organism exhibited transferase activity. Accordingly, purified samples of $\beta$-glucosidases I, III and IV were incubated with glucose plus cellobiose and the products analysed at intervals by TLC. The results illustrated in Fig. 2 show that cellobiose is gradually converted to glucose by $\beta$-glucosidase $\mathrm{I}$, albeit slowly because of inhibition by glucose (McHale \& Coughlan, $1981 \mathrm{~b}$ ), with no spot other than those corresponding to cellobiose or glucose being observed. Similar results were obtained with $\beta$ glucosidase III. In contrast, when $\beta$-glucosidase IV was incubated with cellobiose plus glucose a sugar (arrowed) migrating faster than cellotriose but slower than cellobiose accumulated within half an hour (Fig. 2). The decrease over the next $1.5 \mathrm{~h}$ in the size of the spot corresponding to this unidentified sugar clearly indicated that it was acted on further. The unidentified sugar may be a disaccharide that is converted to glucose in the later stages of incubation or a trisaccharide that is converted to glucose via a disaccharide. Further work will be required to identify the compound(s) and to see whether it (they) induces the synthesis of cellulase by $T$. emersonii. It is interesting that of the $\beta$-glucosidases of this organism which have been purified, only the intracellular form, $\beta$-glucosidase IV, exhibits transferase activity (at the substrate concentrations used). Thus, in keeping with the general scheme proposed by Gong \& Tsao (1979), the intracellular $\beta$-glucosidase I may regulate cellulase synthesis both by converting incoming 
cellobiose to active inducer (transferase action) and cleaving cellobiose to glucose (cellobiase action) repressing cellulase synthesis.

A. McH. thanks the Department of Education, Republic of Ireland, for a maintenance grant. We thank Lynn O'Connor and Dr Denis Headon of this department for their assistance with electrophoretic and isofocusing techniques.

\section{REFERENCES}

ANDREws, P. (1965). The gel filtration behaviour of proteins related to their molecular weights over a wide range. Biochemical Journal 96, 595-605.

Dawson, R. M. C., Elliott, D. C., ElliotT, W. H. \& JONES, K. M. (editors) (1969). Data for Biochemical Research, 2nd edn, p. 541. Oxford: Clarendon Press.

Dubois, M., Gilles, K. A., Hamilton, J. K., Reebers, P. A. \& SMITH, F. (1965). Colorimetric method for determination of sugars and related substances. Analytical Biochemistry 28, 350-356.

Folan, M. A. \& Coughlan, M. P. (1978). The cellulase complex in the culture filtrate of Talaromyces emersonii. International Journal of Biochemistry 9, 717-722.

Folan, M. A. \& Coughlan, M. P. (1981). Cellulase activity of colour 'variants' of Talaromyces emersonii. International Journal of Biochemistry 13, 243-245.

Gong, C. S. \& Tsao, G. T. (1979). Cellulase and biosynthesis regulation. Annual Reports of Fermentation Processes 3, 111-140.

HaRTREe, E. F. (1972). Determination of protein: a modification of the Lowry method that gives a linear photometric response. Analytical Biochemistry 48, 422-427.

HaYashida, S. \& Yoshioka, H. (1980). The role of carbohydrate moiety on thermostability of cellulases from Humicola insolens YH-8. Agricultural and Biological Chemistry 44, 481-487.

Mandels, M. \& Reese, E. T. (1960). Induction of cellulase in fungi by cellobiose. Journal of Bacteriology 79, 816-826.
Mandels, M., Parrish, F. W. \& Reese, E. T. (1962). Sophorose as an inducer of cellulase in Trichoderma reesei. Journal of Bacteriology 83, 400-408.

Margolis, J. \& Kenrick, K. G. (1968). Polyacrylamide gel electrophoresis in a continuous molecular sieve gradient. Analytical Biochemistry 25, 347-362.

Mchale, A. \& Coughlan, M. P. (1980). Synergistic hydrolysis of cellulose by components of the extracellular cellulase system of Talaromyces emersonii. FEBS Letters 117, 319-322.

McHale, A. \& Coughlan, M. P. (1981a). The cellulolytic system of Talaromyces emersonii: identification of the various components produced during growth on cellulosic media. Biochimica et biophysica acta 662 , 145-151.

McHale, A. \& Coughlan, M. P. (1981b). The cellulolytic system of Talaromyces emersonii: purification and characterization of the extracellular and intracellular $\beta$-glucosidases. Biochimica et biophysica acta 662, 152-159.

STERNBERG, D. \& MANDELS, G. R. (1979). Induction of cellulolytic enzymes in Trichoderma reesei by sophorose. Journal of Bacteriology 139, 761-769.

WoOD, T. M. \& MCCRAE, S. I. (1978). The cellulase of Trichoderma koningii. Biochemical Journal 171, 6172.

Zacharius, R. M., Zell, T. E., Morrison, J. H. \& WooDLOCK, J. J. (1969). Glycoprotein staining following electrophoresis on acrylamide gels. Analytical Biochemistry 30, 148-152. 